\title{
Article
}

\section{Effects of prophylactic knee bracing on patellar tendon loading parameters during functional sports tasks in recreational athletes}

Sinclair, Jonathan Kenneth, Richards, James and Taylor, Paul John Available at http://clok.uclan.ac.uk/21080/

Sinclair, Jonathan Kenneth ORCID: 0000-0002-2231-3732, Richards, James ORCID: 0000-0002-4004-3115 and Taylor, Paul John ORCID: 0000-0002-99998397 (2017) Effects of prophylactic knee bracing on patellar tendon loading parameters during functional sports tasks in recreational athletes. Sport Sciences for Health, 14 . pp. 151-160. ISSN 1824-7490

It is advisable to refer to the publisher's version if you intend to cite from the work. http://dx.doi.org/10.1007/s11332-017-0420-3

For more information about UCLan's research in this area go to http://www.uclan.ac.uk/researchgroups/ and search for <name of research Group>.

For information about Research generally at UCLan please go to http://www.uclan.ac.uk/research/

All outputs in CLoK are protected by Intellectual Property Rights law, including Copyright law. Copyright, IPR and Moral Rights for the works on this site are retained by the individual authors and/or other copyright owners. Terms and conditions for use of this material are defined in the policies page. 


\section{functional sports tasks in recreational athletes.}

3 Keywords: Biomechanics, knee brace, patellar tendon, tendinopathy

4 Word count: 3200

5 Conflict statement: No conflict of interest to declare.

6

$7 \quad$ Abstract

8 PURPOSE: This study investigated the effects of prophylactic knee bracing on patellar

9 tendon loading parameters.

METHODS: Twenty recreational athletes (10 male \& 10 female), from a different athletic disciplines performed run, cut and single leg hop movements under two conditions

(prophylactic knee brace/ no-brace). Lower extremity kinetics and kinematics were examined using a piezoelectric force plate, and three-dimensional motion capture system. Patellar tendon loading was explored using a mathematical modelling approach, which accounted for co-contraction of the knee flexors. Tendon loading parameters were examined using 2 $($ brace)*3 (movement)*2 (sex) mixed ANOVA's.

17 RESULTS: Tendon instantaneous load rate was significantly reduced in female athletes, in the run $($ brace $=289.14 \mathrm{BW} / \mathrm{s}$ no-brace $=370.06 \mathrm{BW} / \mathrm{s})$ and cut $($ brace $=353.17 \mathrm{BW} / \mathrm{s} /$ nobrace $=422.01 \mathrm{BW} / \mathrm{s}$ ) conditions whilst wearing the brace.

CONCLUSIONS: Female athletes may be able to attenuate their risk from patellar tendinopathy during athletic movements, through utilization of knee bracing, although further prospective research into the prophylactic effects of knee bracing is required before this can

be clinically substantiated.

\section{Introduction}


Chronic patellar tendinopathy is an extremely common musculoskeletal condition in both recreational and elite athletes, and has previously been reported to account for as many as $25 \%$ of all soft tissue injuries (1). Patellar tendinopathy is characterized by pain localized at the lower pole of the patella, and pain symptoms that are augmented by activities which place high demands on the knee extensors, notably in physical disciplines which repeatedly store and release elastic energy in the tendon itself (2). Patellar tendinopathy is more common in skeletally mature individuals, and there remains disagreement as to whether this condition is most common in male or female athletes (3). Chronic patellar tendinopathy is established after 1-3 months, as degenerative alterations occur in the tendon itself (4). Degenerative alterations at the tendon are mediated primarily by the absence of inflammatory cells within the tendon itself, which reduces healing of the tendon and ultimately leads to decreased tensile strength and disorganization of the collagen fibers (5). Patellar tendinopathy can be debilitating; Cook et al., (6) showed that $1 / 3$ of athletes with patellar tendinopathy are unable to return to physical activity within 6 months, and it has also been evidenced that $53 \%$ of athletes who present with this condition were forced to permanently cease physical activities.

Knee braces are utilized extensively in both recreationally active and competitive athletes, in order to attenuate their risk from knee pathology (7). Knee braces are external devices which are designed to improve the alignment of the knee joint (8). Prophylactic knee braces aim to protect athletes from sustaining injury, whilst being minimally restrictive, allowing athletes to utilize full knee range of motion during their physical activities (9). Recently, the effects of prophylactic knee braces on the biomechanics of the knee joint during dynamic sports tasks have received significant attention in clinical literature. Sinclair et al., (7), examined the effects of knee bracing on knee joint kinetics and kinematics in netball specific movements. They showed that the brace did not alter knee kinetics but did reduce range of motion in the 
51 transverse plane. Ewing et al., (10), examined muscle kinetics with and without the presence

52 of a prophylactic knee brace during double limb drop landings. Hamstring and vasti muscles

53 produced significantly greater flexion and extension torques, and greater peak muscle forces

54 in the brace condition. Lee et al., (11), analyzed the effects of a prophylactic bilateral hinge

55 brace, fitted with torque transducers during four functional sports tasks; drop vertical jump,

56 pivot, stop vertical jump and cut. Their results showed that the knee brace hinges absorbed up

57 to $18 \%$ of the force and $2.7 \%$ of the torque at the knee, during the different athletic motions.

58 Which they concluded, was minimal evidence that the brace was able to reduce the

59 mechanical load at the knee. Although knee braces have been studied in terms of both their

60 therapeutic and prophylactic effects, there is currently no literature which has considered

61 their role in the prevention of patellar tendinopathy.

62

Therefore, the aim of the current investigation was to investigate the effects of a prophylactic knee brace on patellar tendon loading parameters linked to the aetiology of patellar tendinopathy, in male and female recreational athletes. Research of this nature may provide important clinical information, regarding the potential role of prophylactic knee bracing for the prevention of patellar tendinopathy.

68

Methods

Participants

Twenty participants $(10$ male; age $=26.70 \pm 4.24$, mass $=73.90 \pm 5.3$, stature $=176.50 \pm$

$4.25 \& \mathrm{BMI}=23.73 \pm 1.80 \&$ and 10 female age $=27.60 \pm 4.72$, mass $=60.40 \pm 7.86$, stature

$=166.50 \pm 5.06 \& \mathrm{BMI}=21.86 \pm 2.21$, volunteered to take part in the current investigation.

Participants were all recreational level athletes who came from squash, netball, basketball and 
informed consent was provide, $\mathrm{d}$ in accordance with the declaration of Helsinki and the rights of all participants were protected. The procedure was approved by the Universities Science, Technology, Engineering, Medicine and Health ethics committee, with the reference STEMH 295.

\section{Knee Brace}

A single knee brace was utilized in this investigation, (Trizone, DJO USA), which was worn on the dominant limb in all participants. The brace examined in the current investigation represents a compression sleeve reinforced with silicone designed to support the knee joint and improve proprioception.

\section{Procedure}

Participants were required to complete five repetitions of three sports specific movements'; jog, cut and single leg hop, with and without presence of the brace. The order that participants performed in the movement/ brace conditions was counterbalanced. To quantify lower extremity segments, the calibrated anatomical systems technique was utilized (12). Retroreflective markers $(19 \mathrm{~mm})$, were positioned unilaterally allowing the; foot, shank and thigh to be defined. The foot was defined via the 1st and 5th metatarsal heads, medial and lateral malleoli and tracked using the calcaneus, 1st metatarsal and 5th metatarsal heads. The shank was defined via the medial and lateral malleoli and medial and lateral femoral epicondyles and tracked using a cluster positioned onto the shank. The thigh was defined via the medial and lateral femoral epicondyles and the hip joint centre and tracked using a cluster positioned onto the thigh. To define the pelvis additional markers were positioned onto the 
anterior (ASIS) and posterior (PSIS) superior iliac spines and this segment was tracked using

102

103

104 the same markers. The hip joint centre was determined using a regression equation, which uses the positions of the ASIS markers (13). The centers of the ankle and knee joints were delineated as the mid-point between the malleoli and femoral epicondyle markers $(14,15)$. Each tracking cluster comprised four retroreflective markers, mounted onto a rigid piece of lightweight carbon-fibre. Static calibration trials were obtained allowing for the anatomical markers to be referenced in relation to the tracking markers/ clusters. The $\mathrm{Z}$ (transverse) axis was oriented vertically from the distal segment end to the proximal segment end. The Y (coronal) axis was oriented in the segment from posterior to anterior. Finally, the $\mathrm{X}$ (sagittal) axis orientation was determined using the right hand rule and was oriented from medial to lateral.

Data were collected during run, cut and jump movements using the protocol below:

\section{Run}

Participants ran at $4.0 \mathrm{~m} . \mathrm{s}^{-1} \pm 5 \%$, and struck the force platform with their right (dominant) limb. The average velocity of running was monitored using infra-red timing gates (SmartSpeed Ltd UK). The stance phase of running, was defined as the duration over $>20 \mathrm{~N}$ of vertical force was applied to the force platform (16).

\section{Cut}

Participants completed $45^{\circ}$ sideways cut movements, using an approach velocity of $4.0 \mathrm{~m} . \mathrm{s}^{-1}$ $\pm 5 \%$ striking the force platform with their right (dominant) limb. In accordance with McLean et al., (17), cut angles were measured from the centre of the force plate and the corresponding line of movement was delineated using masking tape, so that it was clearly evident to 
participants. The stance phase of the cut-movement was similarly defined as the duration over

$127>20 \mathrm{~N}$ of vertical force was applied to the force platform (16).

129 Hop

130 Participants began standing by on their dominant limb; they were then requested to hop 131 forward maximally, landing on the force platform with same leg without losing balance. The 132 arms were held across the chest to remove arm-swing contribution. The hop movement was defined as the duration from foot contact (defined as $>20 \mathrm{~N}$ of vertical force applied to the 134 force platform), to maximum knee flexion. The hop distance was recorded and maintained 135 throughout data collection.

Processing

Dynamic trials were processed using Qualisys Track Manager, and then exported as C3D files. Ground reaction force and marker data were filtered at $50 \mathrm{~Hz}$ and $15 \mathrm{~Hz}$ respectively using a low-pass Butterworth 4th order filter, and processed using Visual 3-D (C-Motion, Germantown, MD, USA). Internal moments were computed using Newton-Euler inversedynamics, allowing net knee joint moments to be calculated. Angular kinematics of the knee joint were calculated using an XYZ (sagittal, coronal and transverse) sequence of rotations, allowing sagittal angles at footstrike and peak flexion angles to be extracted.

146 A commonly utilized mathematical model for the quantification of patellar tendon loading is 147 that developed by Janssen et al., (18). Whereby the Patellar tendon load is determined by dividing the knee extensor moment by the estimated patellar tendon moment arm. This algorithm has been successfully utilized previously, to resolve differences in patellar tendon 
kinetics during different movements (18), different footwear conditions (19), and also between sexes (20).

However, a limitation of the aforementioned model is that the knee extensor moment does not account for co-contraction of the knee flexor musculature. In order to account for this, we also calculated hamstring and gastrocnemius force in accordance with the procedures described by DeVita and Hortobagyi (21). To summarize, the hamstring force was calculated using the hip extensor moment, hamstrings and gluteus maximus cross-sectional areas (22), and by fitting a $2^{\text {nd }}$ order polynomial curve to the data of Nemeth \& Ohlsen, (23) who provided muscle moment arms at the hip as a function of hip flexion angle. The gastrocnemius force, was calculated firstly by quantifying the ankle plantarflexor force, which was resolved by dividing the plantarflexion moment by the Achilles tendon moment arm. The Achilles tendon moment arm was calculated by fitting a $2^{\text {nd }}$ order polynomial curve to the ankle plantarflexion angle in accordance with Self and Paine (24). The quantity of plantarflexion force accredited to the gastrocnemius muscles, was calculated via the crosssectional area of this muscle relative to the triceps surae (22).

The hamstring and gastrocnemius forces were multiplied by their estimated muscle moment arms to the knee joint in relation to the knee flexion angle (25), and then added together to estimate the knee flexor moment. The derived knee flexor moment was added to the net knee extensor moment quantified using inverse dynamics, and then divided by the moment arm of the patellar tendon, generating the patellar tendon force. The tendon moment arm was quantified as a function of the sagittal plane knee angle, by fitting a $2^{\text {nd }}$ order polynomial curve to the data provided by Herzog \& Read, (26), showing patellar tendon moment arms at different knee flexion angles. 
176 All patellar tendon load parameters were normalized by dividing the net values by 177 bodyweight (BW). Patellar tendon instantaneous load rate (BW/s), was quantified as the peak 178 increase in patellar tendon force between adjacent data points. In addition, we also calculated 179 the total patellar tendon force impulse $(\mathrm{BW} \cdot \mathrm{s})$ during each movement using a trapezoidal 180 function.

Statistical analyses

Descriptive statistics of means, standard deviations and $95 \%$ confidence intervals (95\% CI) were obtained for each outcome measure. Shapiro-Wilk tests were used to screen the data for normality. Differences in patellar tendon loading parameters between conditions, were examined using 2 (brace) $* 3$ (movement) $* 2$ (sex) mixed ANOVA's. Statistical significance was accepted at the $\mathrm{P}<0.05$ level. Effect sizes for all significant findings were calculated using partial $\mathrm{Eta}^{2}\left(\mathrm{p \eta}^{2}\right)$. Post-hoc pairwise comparisons were conducted on all significant main effects. Significant interactions were further evaluated by performing simple main effect examinations on each level of the interaction, in the event of a significant simple main effect pairwise comparisons were performed. All statistical actions were conducted using SPSS v22.0 (SPSS Inc, Chicago, USA).

Results

Tables 1-4 and figure 1 present patellar tendon loading parameters as a function of brace, movement and sex. 
Peak patellar tendon force

A significant main effect $\left(\mathrm{P}<.05, \mathrm{p \eta}^{2}=.20\right)$ was found for movement. Post-hoc pairwise comparisons showed that peak patellar tendon force was significantly larger in the cut movement compared to the hop $(\mathrm{P}=.046)$ and run $(\mathrm{P}=.008)$ conditions.

In addition a significant main effect $\left(\mathrm{P}<.05, \mathrm{p}^{2}=.31\right)$ was observed for brace. Post-hoc pairwise comparisons showed that peak patellar tendon force was significantly larger in the no-brace $(\mathrm{P}=.013)$ condition compared to wearing the brace.

Patellar tendon instantaneous load rate

A significant main effect $\left(\mathrm{P}<.05, \mathrm{p \eta}^{2}=.29\right)$ was found for movement. Post-hoc pairwise comparisons showed that patellar tendon instantaneous load rate was significantly larger in the cut $(\mathrm{P}=.032)$ and hop $(\mathrm{P}=.003)$ conditions compared to the run movement. In addition a significant main effect $\left(\mathrm{P}<.05, \mathrm{p} \eta^{2}=.45\right)$ was observed for brace, with patellar tendon instantaneous load rate being significantly in the no-brace condition compared to wearing the brace.

222 Finally a significant $\left(\mathrm{P}<.05, \mathrm{p} \eta^{2}=.19\right)$ brace * movement $*$ sex interaction was shown. 223 Follow up analyses using simple main effects showed for males that a there was a significant 224 main effect $\left(\mathrm{P}<.05, \mathrm{p \eta}^{2}=.21\right)$ for movement, with the hop $(\mathrm{P}=.01)$ and cut $(\mathrm{P}=.04)$ 
movements being associated with a greater instantaneous load rate than the run movement.

226 For females there was a significant main effect $\left(\mathrm{P}<.05, \mathrm{p} \eta^{2}=.86\right)$ for movement, with the hop

227

228

$(\mathrm{P}=.00001)$ and cut $(\mathrm{P}=.002)$ movements being associated with a greater instantaneous load rate than the run movement. In addition there was also a main effect $\left(\mathrm{P}<.05, \mathrm{p} \eta^{2}=.57\right)$ for brace with instantaneous load rate being significantly $(\mathrm{P}=.018)$ larger in the no-brace condition. Finally a significant $\left(\mathrm{P}<.05, \mathrm{p}^{2}=.42\right)$ brace $*$ movement interaction was found for females. Follow up analyses showed that there were main effects for the run $\left(\mathrm{P}<.05, \mathrm{p} \eta^{2}=\right.$ $.89)$ and cut $\left(\mathrm{P}<.05, \mathrm{p}^{2}=.72\right)$ movements, with instantaneous load rate being significantly greater in the no-brace condition for both movements (cut $-\mathrm{P}=.004 \&$ run $-\mathrm{P}=.00001$ ). No differences were shown for the hop condition.

\section{Patellar tendon impulse}

A significant main effect $\left(\mathrm{P}<.05, \mathrm{p \eta}^{2}=.20\right)$ was found for movement. Post-hoc pairwise comparisons showed that peak tendon impulse was significantly larger in the cut $(\mathrm{P}=.0002)$ and hop $(\mathrm{P}=.048)$ movements compared to the run condition.

In addition a significant main effect $\left(\mathrm{P}<.05, \mathrm{p}^{2}=.19\right)$ was observed for brace, with patellar tendon impulse was significantly larger in the no-brace $(\mathrm{P}=.042)$ condition compared to wearing the brace.

Finally, a significant $\left(\mathrm{P}<.05, \mathrm{p \eta}^{2}=.19\right)$ brace $*$ movement $*$ sex interaction was shown. Follow up analyses using simple main effects showed for males that a there was a significant main effect $\left(\mathrm{P}<.05, \mathrm{p}^{2}=.35\right)$ for movement, with the hop $(\mathrm{P}=.001)$ and cut $(\mathrm{P}=.023)$ movements being associated with a greater impulse than the run movement. For females there was a significant main effect $\left(\mathrm{P}<.05, \mathrm{p} \eta^{2}=.22\right)$ for movement, with the cut $(\mathrm{P}=.01)$ being 
associated with a greater impulse than the run movement. Finally a significant $\left(\mathrm{P}<.05, \mathrm{p} \eta^{2}=\right.$ .56) brace * movement interaction was found for females. Follow up analyses showed that there was a main effect for the run $\left(\mathrm{P}<.05, \mathrm{p} \eta^{2}=.89\right)$ movement, with impulse being significantly $(\mathrm{P}=.0004)$ greater in the no-brace condition.

\section{Sagittal knee kinematics}

For the knee flexion angle at footstrike, a significant main effect $\left(\mathrm{P}<.05, \mathrm{p} \eta^{2}=.36\right)$ was observed for brace, with knee flexion being reduced in the brace condition. For the peak flexion angle, a significant main effect $\left(\mathrm{P}<.05, \mathrm{p}^{2}=.28\right)$ was observed for brace, with peak flexion being reduced in the brace condition. In, addition, a significant main effect $(\mathrm{P}<.05$, $\left.\mathrm{p \eta}^{2}=.60\right)$ was observed for movement. Post-hoc pairwise comparisons indicated that peak flexion was significantly greater in the cut $(\mathrm{P}=.000008)$ and hop $(\mathrm{P}=.0000009)$ movement in comparison to the run and also in the hop compared to the cut $(\mathrm{P}=.02)$. Finally, a significant brace $* \operatorname{sex}\left(\mathrm{P}<.05, \mathrm{p \eta}^{2}=.22\right)$ interaction was found. Follow up analyses showed that in female athletes only peak knee flexion was significantly reduced in the brace condition for the run $\left(\mathrm{P}<.05, \mathrm{p}^{2}=.37\right)$ and hop $\left(\mathrm{P}<.05, \mathrm{p}^{2}=.66\right)$ movements.

\section{Discussion}

The aim of the current investigation was to investigate the effects of a prophylactic knee brace on patellar tendon loading parameters linked to the aetiology of patellar tendinopathy, in male and female recreational athletes. To the authors' knowledge, this represents the first investigation to examine the effects of prophylactic knee bracing in relation to the aetiology patellar tendinopathy. 
274 A key finding from the current study is that indices of patellar tendon instantaneous load rate

275 and impulse were found to be significantly reduced in female athletes during the run and cut

276 movements when wearing the knee brace. This observation is interesting in that female

277 athletes exhibited significant reductions in patellar tendon loading parameters as a function of

278 the prophylactic brace, yet in male athletes there were no statistical alterations. The

279 mechanisms responsible for this observation are unknown at this stage. However, previous

280 analyses have shown that female's exhibit diminished knee joint proprioception in relation to

males (27-30). Prophylactic knee sleeves, such as that used in the current investigation are

proposed to promote stimulation of type $\delta$ sensory fibres within skin mechanoreceptors (31),

and clinical research into their efficacy has shown that they are associated with improvements

in knee joint proprioception (32-34). It can be speculated upon that there may be more scope

for proprioceptive benefits in females, and that the positive effect of the knee brace in female

athletes was mediated by a proprioceptive effect, which may have been responsible for the

alterations in peak knee flexion that were evident only in female participants. Reductions in

knee flexion are associated with lengthening of the moment arm of the patellar tendon itself,

which leads to a reduction in tendon loading. Nonetheless, further mechanistic investigations

into the specific effects of prophylactic knee sleeves on joint position sense at the knee are

required before this notion can be recognized.

292

293 As stated previously, the aetiology of patellar tendinopathy in athletic populations, relates to

294 the storage and release of energy by the tendon during sports movements (2). Therefore given the increased rate at which the tendon was loaded in the no-brace condition, this observation may have clinical significance. It can be conjectured that female athletes may be able to 
A further important observation from this investigation, is that for both male and female athletes, patellar tendon loading was significantly greater in the cut and hop movements in relation to the run condition. It is proposed that this observation relates to the ballistic nature of cut and single leg hop movements, in relation to the run condition, placing greater demands on the knee extensors. It has been shown through epidemiological analyses, that the aetiology of patellar tendinopathy is related to the magnitude of the loads experienced by the tendon itself (2). Importantly, cutting is one of the key abilities of sports games (35) and

A potential drawback to the current investigation is that patellar tendon loading parameters were quantified via a musculoskeletal driven model. Although this approach represents an

including but not limited to; association football (36), American football (37), netball (4), tennis (38), squash (16) and basketball (39). In addition, single leg hop landings are similarly common in multidirectional sports including but not limited to; association football (40), American football (41), gymnastics (42), netball (7) and basketball (39). The findings from the current investigation indicate that cut and hop motions may place athletes at increased risk from patellar tendon pathology, therefore conservative prophylactic measures such as knee bracing may be important apparatuses in athletic disciplines and their associated training regimens whereby these movements are common. Future prospective research is clearly required to investigate the longitudinal prophylactic effects of different conservative modalities, in sports which place high mechanical demands on the patellar tendon. advancement in relation to previous mechanisms, further progression is needed to improve 
the efficacy of musculoskeletal modeling of patellar tendon kinetics. Although muscle driven simulations of musculoskeletal loading require a range of mechanical assumptions, they have developed significantly in recent years. Thus, musculoskeletal simulations have the potential to become useful tools for clinical analyses in the field of biomechanics.

In conclusion, whilst previous analyses have investigated the therapeutic and prophylactic effects of knee bracing, the current knowledge with regards to the effects of prophylactic knee bracing on the patellar tendon in functional athletic movements is limited. The current investigation therefore addresses this, by examining the effects of wearing a prophylactic knee brace on patellar tendon loading parameters during run, cut and jump movements in male and female athletes. The current study showed firstly that patellar tendon loading parameters were significantly reduced in female athletes in the run and cut conditions whilst wearing the brace. In addition, for both males and females the cut and hop movements were associated with significantly greater tendon loading in relation to the run motion. Given the association between patellar tendon loading and the aetiology of patellar tendinopathy, this observation may be clinically important. It can be conjectured that female athletes may be able to attenuate their risk from tendinopathy during specific athletic movements through utilization of knee bracing, although further prospective research into the prophylactic effects of knee bracing is required before this can be clinically substantiated.

\section{References}

1. Lian, Ø.B., Engebretsen, L., and Bahr, R. Prevalence of jumper's knee among elite athletes from different sports a cross-sectional study. American Journal of Sports Medicine. 2005; 33: 561-567. 
2. Rudavsky, A., and Cook, J. Physiotherapy management of patellar tendinopathy. Journal of Physiotherapy. 2014; 60: 122-129.

3. Witvrouw, E., Bellemans, J., Lysens, R., Danneels, L., and Cambier, D. Intrinsic risk factors for the development of patellar tendinitis in an athletic population: a two-year prospective study. American Journal of Sports Medicine. 2001; 29: 190-195.

4. Maffulli, N., Wong, J., and Almekinders, L.C. Types and epidemiology of tendinopathy. Clinical Journal of Sports Medicine. 2003; 22: 675-692.

5. Cook, J.L., Khan, K.M., Harcourt, P.R., Grant, M., Young, D.A., and Bonar, S.F. A cross sectional study of 100 athletes with jumper's knee managed conservatively and surgically. The Victorian Institute of Sport Tendon Study Group. British Journal of Sports Medicine. 1997; 31: 332-336.

6. Cook, J.L., Khan, K.M, and Purdam, C.R. Conservative treatment of patellar tendinopathy. Physical Therapy in Sport. 2001; 35: 291-294.

7. Sinclair, J., Vincent, H., Richards, J. Effects of prophylactic knee bracing on knee joint kinetics and kinematics during netball specific movements. Physical Therapy in Sport. 2017; 23: 93-98.

8. Paluska, S.A., and McKeag, D.B. Knee braces: current evidence and clinical recommendations for their use. American Family Physician. 2000; 61: 411-418.

9. Warden, S.J., Hinman, R.S., Watson, M.A., Avin, K.G., Bialocerkowski, A.E., and Crossley, K.M. Patellar taping and bracing for the treatment of chronic knee pain: A systematic review and meta-analysis. Arthritis Care \& Research. 2008; 59: 73-83.

10. Ewing, K.A., Fernandez, J.W., Begg, R.K., Galea, M.P., and Lee, P.V. Prophylactic knee bracing alters lower-limb muscle forces during a double-leg drop landing. Journal of Biomechanics. 2016; 49; 3347-3354. 
11. Lee, H., Ha, D, Kan, Y.S., and Park, H.S. Biomechanical Analysis of the Effects of Bilateral Hinged Knee Bracing. Frontiers in Bioengineering and Biotechnology. 2016; 4: 50-55.

12. Cappozzo, A., Catani, F., Leardini, A., Benedeti, M.G., and Della C.U. Position and orientation in space of bones during movement: Anatomical frame definition and determination. Clinical Biomechanics. 1995; 10: 171-178.

13. Sinclair, J., Taylor, P.J., Currigan, G., and Hobbs, S.J. The test-retest reliability of three different hip joint centre location techniques. Movement \& Sport Sciences. 2014; 83: 31-39.

14. Sinclair, J., Hebron, J., and Taylor, P.J. The Test-retest Reliability of Knee Joint Center Location Techniques. Journal of Applied Biomechanics. 2015; 31: 117-121.

15. Graydon, R., Fewtrell, D., Atkins, S., and Sinclair, J. The test-retest reliability of different ankle joint center location techniques. Foot \& Ankle Online Journal. 2015; 8: $1-11$.

16. Sinclair, J., Hobbs, S.J., Protheroe, L., Edmundson, C.J., and Greenhalgh, A. Determination of gait events using an externally mounted shank accelerometer. Journal of Applied Biomechanics. 2013; 29: 118-122.

17. McLean, S.G., Huang, X., Su, A., and Van Den Bogert, A.J. Sagittal plane biomechanics cannot injure the ACL during sidestep cutting. Clinical Biomechanics. 2004; 19: 828-838.

18. Janssen, I., Steele, J.R., Munro, B.J., and Brown, N.A. Predicting the patellar tendon force generated when landing from a jump. Medicine \& Science in Sport \& Exercise. 2013; 45: 927-934. 
19. Sinclair, J, and Taylor, PJ. Effects of court specific and minimalist footwear on patellar tendon loading during a maximal change of direction task. Baltic Journal of Physical Activity in Health (In Press).

20. Sinclair, J., and Taylor, P.J. Sex variation in patellar tendon kinetics during running. Human Movement. 2015; 16: 60-63.

21. DeVita, P., and Hortobagyi, T. Functional knee brace alters predicted knee muscle and joint forces in people with ACL reconstruction during walking. Journal of Applied Biomechanics. 2001; 17: 297-311.

22. Ward, S.R., Eng, C.M., Smallwood, L.H., and Lieber, R.L. Are current measurements of lower extremity muscle architecture accurate? Clinical Orthopaedics and Related Research. 2009; 467: 1074-1082.

23. Nemeth, G., and Ohlsen, H. In vivo moment arm lengths for hip extensor muscles at different angles of hip flexion. Journal of Biomechanics. 1985; 18: 129-140.

24. Self, B.P., and Paine, D. Ankle biomechanics during four landing techniques. Medicine \& Science in Sports \& Exercise. 2001; 33: 1338-1344.

25. Spoor, C.W., van Leeuwen, J.L. Knee muscle moment arms from MRI and from tendon travel. Journal of Biomechanics. 1992; 25: 201-206.

26. Herzog, W., and Read, L.J. Lines of action and moment arms of the major forcecarrying structures crossing the human knee joint. Journal of Anatomy. 1993; 182: 213-230.

27. Nagai, T., Sell, T.C., Abt, J.P., and Lephart, S.M. Reliability, precision, and gender differences in knee internal/external rotation proprioception measurements. Physical Therapy in Sport. 2012; 13: 233-237. 
28. Muaidi, Q.I. Does gender make a difference in knee rotation proprioception and range of motion in healthy subjects?. Journal of Back and Musculoskeletal Rehabilitation. 2017; (In press).

29. Rozzi, S.L., Lephart, S.M., Gear, W.S., and Fu, F.H. Knee joint laxity and neuromuscular characteristics of male and female soccer and basketball players. The American Journal of Sports Medicine. 1999; 27: 312-319.

30. Karkousha, R.N. Sex differences of knee joint repositioning accuracy in healthy adolescents. Bulletin of Faculty of Physical Therapy. 2016; 21: 56-60.

31. Callaghan, M.J., Selfe, J., McHenry, A., and Oldham, J. A. Effects of patellar taping on knee joint proprioception in patients with patellofemoral pain syndrome. Manual Therapy. 2008; 13: 192-199.

32. Baltaci, G., Aktas, G., Camci, E., Oksuz, S., Yildiz, S., and Kalaycioglu, T. The effect of prophylactic knee bracing on performance: balance, proprioception, coordination, and muscular power. Knee Surgery, Sports Traumatology, Arthroscopy. 2011; 19: $1722-1728$.

33. Herrington, L., Simmonds, C., and Hatcher, J. The effect of a neoprene sleeve on knee joint position sense. Research in Sports Medicine. 2005; 13: 37-46.

34. McNair, P.J., Stanley, S.N., and Strauss, G.R. Knee bracing: effects on proprioception. Archives of Physical Medicine and Rehabilitation. 1996; 77: 287-289.

35. Sheppard, J.M., and Young, W.B. Agility literature review: classifications, training and testing. Journal of Sports Sciences. 2006; 24: 919-932.

36. Strutzenberger, G., Cao, H. M., Koussev, J., Potthast, W., and Irwin, G. Effect of turf on the cutting movement of female football players. Journal of Sport and Health Science. 2014; 3: 314-319. 
37. Carson, D.W., Myer, G.D., Hewett, T.E., Heidt, R. S., and Ford, K.R. Increased plantar force and impulse in American football players with high arch compared to normal arch. The Foot 2012; 22: 310-314.

38. Stacoff, A., Steger, J., Stuessi, E., and Reinschmidt, C. Lateral stability in sideward cutting movements. Medicine \& Science in Sport \& Exercise. 1996; 28: 350-358.

39. Cowley, H.R., Ford, K.R., Myer, G.D., Kernozek, T.W., and Hewett, T.E. Differences in neuromuscular strategies between landing and cutting tasks in female basketball and soccer athletes. Journal of Athletic Training. 2006; 41: 67-73.

40. Lyle, M.A., Valero-Cuevas, F.J., Gregor, R.J., and Powers, C.M. Control of dynamic foot-ground interactions in male and female soccer athletes: females exhibit reduced dexterity and higher limb stiffness during landing. Journal of Biomechanics. 2014; 47: $512-517$.

41. Masters, C., Johnstone, J., and Hughes, G. The Effect of Arm Position on Lower Extremity Kinematics during a Single Limb Drop Landing: A Preliminary Study. Journal of Functional Morphology and Kinesiology. 2016; 1: 282-288.

42. Chaudhari, A.M., Hearn, B.K., and Andriacchi, T.P. Sport-dependent variations in arm position during single-limb landing influence knee loading. The American journal of $\quad$ Sports $\quad$ Medicine. $\quad 2005 ; \quad 33: \quad 824-830$. 
459 Table 1: Patellar tendon load parameters (means, standard deviations and $95 \%$ confidence intervals) as a function of brace and movement

460 conditions in male athletes.

\begin{tabular}{|c|c|c|c|c|c|c|c|c|c|c|c|c|c|c|c|c|c|c|}
\hline & \multicolumn{18}{|c|}{ Male } \\
\hline & \multicolumn{6}{|c|}{ Run } & \multicolumn{6}{|c|}{ Cut } & \multicolumn{6}{|c|}{ Hop } \\
\hline & \multicolumn{3}{|c|}{ Brace } & \multicolumn{3}{|c|}{ No-Brace } & \multicolumn{3}{|c|}{ Brace } & \multicolumn{3}{|c|}{ No-Brace } & \multicolumn{3}{|c|}{ Brace } & \multicolumn{3}{|c|}{ No-Brace } \\
\hline & Mean & SD & $\begin{array}{c}95 \% \\
\mathrm{Cl} \\
\end{array}$ & Mean & SD & \begin{tabular}{|c|}
$95 \%$ \\
$\mathrm{Cl}$ \\
\end{tabular} & Mean & SD & $\begin{array}{c}95 \% \\
\mathrm{Cl} \\
\end{array}$ & Mean & SD & $\begin{array}{c}95 \% \\
\mathrm{Cl} \\
\end{array}$ & Mean & SD & \begin{tabular}{|c|}
$95 \%$ \\
$\mathrm{Cl}$ \\
\end{tabular} & Mean & SD & $\begin{array}{c}95 \% \\
\mathrm{Cl}\end{array}$ \\
\hline $\begin{array}{l}\text { Peak patellar tendon load } \\
\text { (BW) }\end{array}$ & 7.03 & 1.25 & $\begin{array}{c}6.24- \\
7.83\end{array}$ & 7.48 & 1.48 & $\begin{array}{c}6.54- \\
8.42\end{array}$ & 8.08 & 2.03 & $\begin{array}{l}6.80- \\
9.37\end{array}$ & 8.30 & 1.46 & $\begin{array}{c}7.37- \\
9.22\end{array}$ & 7.76 & 1.67 & $\begin{array}{c}6.69- \\
8.82\end{array}$ & 8.07 & 1.22 & $\begin{array}{c}7.30- \\
8.85\end{array}$ \\
\hline $\begin{array}{c}\text { Patellar tendon } \\
\text { instantaneous load rate } \\
\text { (BW/s) }\end{array}$ & 335.41 & 115.57 & $\begin{array}{c}261.98 \\
- \\
408.84\end{array}$ & 358.54 & 114.05 & $\begin{array}{c}286.07 \\
- \\
431.01\end{array}$ & 445.64 & 162.25 & $\begin{array}{c}342.55 \\
- \\
548.73\end{array}$ & 457.89 & 153.72 & $\begin{array}{c}360.22 \\
- \\
555.56\end{array}$ & 442.39 & 184.86 & $\begin{array}{c}324.94 \\
- \\
559.85\end{array}$ & 518.55 & 270.58 & $\begin{array}{c}346.63 \\
- \\
690.49\end{array}$ \\
\hline $\begin{array}{l}\text { Patellar tendon impulse } \\
\text { (BW·s) }\end{array}$ & 0.61 & 0.13 & $\begin{array}{c}0.52- \\
0.69\end{array}$ & 0.82 & 0.25 & $\begin{array}{l}0.66- \\
0.97\end{array}$ & 1.01 & 0.31 & $\begin{array}{c}0.81- \\
1.21\end{array}$ & 0.98 & 0.30 & $\begin{array}{c}0.79- \\
1.17\end{array}$ & 1.01 & 0.50 & $\begin{array}{c}0.69- \\
1.32\end{array}$ & 0.96 & 0.38 & $\begin{array}{c}0.72- \\
1.20\end{array}$ \\
\hline
\end{tabular}

461

462

463

464

465

466

467

468

469

470

471

472

473 
474 Table 2: Patellar tendon load parameters (means, standard deviations and 95\% confidence intervals) as a function of brace and movement

475 conditions in female athletes.

\begin{tabular}{|c|c|c|c|c|c|c|c|c|c|c|c|c|c|c|c|c|c|c|}
\hline & \multicolumn{18}{|c|}{ Female } \\
\hline & \multicolumn{6}{|c|}{ Run } & \multicolumn{6}{|c|}{ Cut } & \multicolumn{6}{|c|}{ Hop } \\
\hline & \multicolumn{3}{|c|}{ Brace } & \multicolumn{3}{|c|}{ No-Brace } & \multicolumn{3}{|c|}{ Brace } & \multicolumn{3}{|c|}{ No-Brace } & \multicolumn{3}{|c|}{ Brace } & \multicolumn{3}{|c|}{ No-Brace } \\
\hline & Mean & SD & $\begin{array}{c}95 \% \\
\mathrm{Cl}\end{array}$ & Mean & SD & $\begin{array}{c}95 \% \\
\mathrm{Cl}\end{array}$ & Mean & SD & $95 \% \mathrm{Cl}$ & Mean & SD & $\begin{array}{c}95 \% \\
\mathrm{Cl}\end{array}$ & Mean & SD & $\begin{array}{c}95 \% \\
\mathrm{Cl}\end{array}$ & Mean & SD & $\begin{array}{c}95 \% \\
\mathrm{Cl}\end{array}$ \\
\hline $\begin{array}{l}\text { Peak patellar tendon load } \\
\text { (BW) }\end{array}$ & 7.69 & 0.76 & $\begin{array}{c}7.05- \\
8.32\end{array}$ & 9.42 & 1.03 & $\begin{array}{l}8.56- \\
10.29\end{array}$ & 8.79 & 1.14 & $\begin{array}{c}7.84- \\
9.73\end{array}$ & 9.26 & 1.93 & \begin{tabular}{|l|}
$7.64-$ \\
10.87
\end{tabular} & 7.88 & 0.76 & $\begin{array}{c}7.24- \\
8.52\end{array}$ & 8.70 & 2.38 & $\begin{array}{l}6.72- \\
10.69\end{array}$ \\
\hline $\begin{array}{c}\text { Patellar tendon } \\
\text { instantaneous load rate } \\
\text { (BW/s) }\end{array}$ & 289.14 & 65.59 & $\begin{array}{c}234.31 \\
- \\
343.98\end{array}$ & 370.06 & 93.67 & $\begin{array}{l}291.75 \\
- \\
488.40\end{array}$ & 353.17 & 116.46 & $\begin{array}{c}255.81 \text { - } \\
450.54\end{array}$ & 422.01 & 142.91 & $\begin{array}{c}302.54 \\
- \\
541.49\end{array}$ & 484.43 & 63.87 & $\begin{array}{c}431.0 . \\
- \\
537.83\end{array}$ & 487.58 & 115.96 & $\begin{array}{c}390.64 \\
- \\
584.53\end{array}$ \\
\hline $\begin{array}{l}\text { Patellar tendon impulse } \\
\text { (BW·s) }\end{array}$ & 0.79 & 0.10 & $\begin{array}{l}0.70- \\
0.87\end{array}$ & 1.00 & 0.07 & $\begin{array}{c}0.94- \\
1.05\end{array}$ & 0.95 & 0.12 & $\begin{array}{l}0.89- \\
1.05\end{array}$ & 1.05 & 0.19 & \begin{tabular}{|c|}
$0.90-$ \\
1.25
\end{tabular} & 0.84 & 0.09 & $\begin{array}{c}0.76- \\
0.91\end{array}$ & 0.99 & 0.42 & $\begin{array}{c}0.64- \\
1.34\end{array}$ \\
\hline
\end{tabular}

478 Table 3: Knee flexion parameters (means, standard deviations and 95\% confidence intervals) as a function of brace and movement conditions in 479 male athletes.

\begin{tabular}{|c|c|c|c|c|c|c|c|c|c|c|c|c|c|c|c|c|c|c|}
\hline & \multicolumn{18}{|c|}{ Male } \\
\hline & \multicolumn{6}{|c|}{ Run } & \multicolumn{6}{|c|}{ Cut } & \multicolumn{6}{|c|}{ Hop } \\
\hline & \multicolumn{3}{|c|}{ Brace } & \multicolumn{3}{|c|}{ No-Brace } & \multicolumn{3}{|c|}{ Brace } & \multicolumn{3}{|c|}{ No-Brace } & \multicolumn{3}{|c|}{ Brace } & \multicolumn{3}{|c|}{ No-Brace } \\
\hline & Mean & SD & $95 \% \mathrm{Cl}$ & Mean & SD & $95 \% \mathrm{Cl}$ & Mean & SD & $95 \% \mathrm{Cl}$ & Mean & SD & $95 \% \mathrm{Cl}$ & Mean & SD & $95 \% \mathrm{Cl}$ & Mean & SD & $\begin{array}{c}95 \% \\
\mathrm{Cl}\end{array}$ \\
\hline $\begin{array}{c}\text { Angle at } \\
\left.\text { footstrike ( }{ }^{\circ}\right)\end{array}$ & 10.92 & 4.34 & $8.16-16.68$ & 13.30 & 5.98 & $9.50-17.10$ & 10.26 & 4.48 & $7.42-13.11$ & 12.67 & 5.76 & $9.01-16.32$ & 12.94 & 6.29 & $8.95-16.94$ & 13.70 & 3.16 & $\begin{array}{l}11.70 \\
15.71 \\
\end{array}$ \\
\hline Peak flexion ( $\left(^{\circ}\right)$ & 36.55 & 2.64 & $\begin{array}{c}34.87- \\
38.23\end{array}$ & 39.05 & 4.06 & $36.47-41.63$ & 44.45 & 4.18 & $41.79-47.10$ & 43.92 & 3.82 & $41.50-46.35$ & 45.26 & 6.60 & $\begin{array}{l}41.07- \\
49.46\end{array}$ & 45.00 & 5.79 & \begin{tabular}{|l|}
41.32 \\
48.68 \\
\end{tabular} \\
\hline
\end{tabular}




\begin{tabular}{|c|c|c|c|c|c|c|c|c|c|c|c|c|c|c|c|c|c|c|}
\hline & \multicolumn{18}{|c|}{ Female } \\
\hline & \multicolumn{6}{|c|}{ Run } & \multicolumn{6}{|c|}{ Cut } & \multicolumn{6}{|c|}{ Hop } \\
\hline & \multicolumn{3}{|c|}{ Brace } & \multicolumn{3}{|c|}{ No-Brace } & \multicolumn{3}{|c|}{ Brace } & \multicolumn{3}{|c|}{ No-Brace } & \multicolumn{3}{|c|}{ Brace } & \multicolumn{3}{|c|}{ No-Brace } \\
\hline & Mean & SD & $95 \% \mathrm{Cl}$ & Mean & SD & $95 \% \mathrm{Cl}$ & Mean & SD & $95 \% \mathrm{Cl}$ & Mean & SD & $95 \% \mathrm{Cl}$ & Mean & SD & $95 \% \mathrm{Cl}$ & Mean & SD & $95 \% \mathrm{Cl}$ \\
\hline $\begin{array}{c}\text { Angle at } \\
\text { footstrike }\left({ }^{\circ}\right)\end{array}$ & 11.46 & 2.66 & $9.24-13.69$ & 16.44 & 4.94 & $\begin{array}{l}12.31- \\
20.57\end{array}$ & 13.16 & 3.98 & $9.83-16.49$ & 17.87 & 4.53 & $14.09-21.65$ & 12.49 & 3.14 & $9.86-15.12$ & 17.99 & 6.27 & $\begin{array}{l}12.74- \\
23.23\end{array}$ \\
\hline Peak flexion $\left({ }^{\circ}\right)$ & 36.64 & 1.92 & $\begin{array}{c}35.04- \\
38.25\end{array}$ & 41.12 & 3.84 & $\begin{array}{l}37.91- \\
44.33\end{array}$ & 44.35 & 2.12 & $\begin{array}{c}42.85- \\
46.12\end{array}$ & 45.71 & 3.12 & $43.10-48.32$ & 49.74 & 8.48 & $\begin{array}{c}42.65- \\
56.83\end{array}$ & 53.39 & 11.50 & $\begin{array}{c}43.78- \\
63.00\end{array}$ \\
\hline
\end{tabular}

482

483

484

$485 \quad$ List of figures

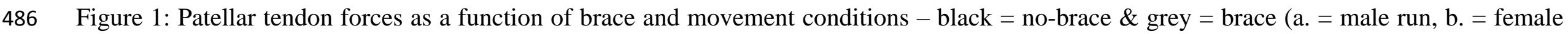

487 run, c. = male cut, d. = female cut, e. = male hop and f. = female hop). 